\title{
NOTAS SOBRE LA LIBERTAD DE PENSAMIENTO EN ESPAÑA DURANTE EL SIGLO DE LA ILUSTRACIÓN
}

Cuando en 1941 A.J. Carlyle publica su obra La libertad política, incluye, con la ayuda declarada de Fernando de los Ríos, un capítulo sobre el desarrollo en España de tal pieza jurídico-política en la historia del constitucionalismo moderno. Por preferencia de los autores, probablemente de quien aparecía como colaborador, F. de los Ríos, es relativamente amplia la referencia a escritores del que con frecuencia se llama —sin gusto por mi parte- "Siglo de Oro"': Covarrubias, Mariana, Rivadeneyra, y también Saavedra Fajardo, precedidos por una mera alusión personal a Vitoria, Soto, Suárez y Molina, con exclusión total de Vives, Fox Morcillo, Furió Ceriol, Las Casas y, al final, de R. Arriaga. Carlyle confiesa que no ha encontrado nada de interés en el XviII y salta a comienzos del XIX, para dedicar algunas páginas exclusivamente a Martínez Marma y con él pone fin al capítulo ${ }^{1}$.

Creo que algo se puede recoger sobre el pensamiento de la libertad política en la centuria de la Ilustración, y quizá más interesante de lo que seleccionaron Carlyle y de los Ríos. Pero mientras tengo ocasión de ocuparme con más amplio panorama y mayor extensión del tema, me limitaré aquí a dar algunas notas sobre la libertad de expresión del pensamiento que en el siglo XviI es, tal vez, el aspecto más vivo y discutido de la libertad política, puesto que afecta a la relación del ciudadano con los más altos centros de poder, el Príncipe y la Iglesia.

La profesora L. Domergue ha estudiado el tema desde su lado negativo: la censura y los medios de control ideológico puestos en práctica por el regalismo y el dirigismo gubernativo ilustrado. Ésta es, sin duda, la parte más importante de la cuestión. Ni formalmente, en derecho, ni de hecho socialmente, aparece ninguna concesión a la libertad de pensamiento, y la autora tiene razón de escribir: "le problème de la liberté ne se posa pas d'entrée et de façon directe sur un plan politique, mais simplement économique. Pas même sur un plan intellectuel ou religieux, comme il s'est posé dans d'autres pays européens, en France par

1 Alexander J. Carlyle, La libertad política, trad. de V. Herrero, México, 1942, pp. 109 ss. 
exemple",2. Pero con esto no queda dicho todo, como la misma autora nos hace comprender en otra de sus obras ${ }^{3}$. Un buen número de ilustrados - y sin duda se podrían añadir más a los que aquí se citan-tratan de pasar de los planes de reforma económica y administrativa a pretensiones de reforma científica, más tempranamente, y en el último tercio del siglo, también de reforma política y aun con cierto radicalismo, bien expresándose en términos velados, bien semidescubiertos, bien francamente expuestos. De esta cuestión me he ocupado en trabajos anteriores (algunos de los cuales cito más adelante). Aquí no pretendo más que recoger algunas notas que vienen a completar, en este aspecto, el excelente trabajo de la profesora Domergue. Por otra parte, siempre en los ilustrados se encuentran restricciones y límites: en Voltaire, de la libertad de enseñanza, para acentuar sobre todo la libertad de conciencia; en Kant, al centrar su interés en esta última, y desentenderse de la libertad política; en Hume, al poner límites a la investigación científica, y defender la aplicación de un análisis lógico de plena libertad en el pensamiento sobre la religión, la ética y la política. A estas costas no llegan tampoco los ilustrados españoles, aunque algunos las vislumbran y aun quisieran dirigir sus pasos hacia ellas ${ }^{4}$.

No voy a negar que esa labor intelectual que los escritores del siglo de las "luces" realizan en España se pueda estimar análoga a la que se produce en Francia; pero sí que se muestra emparentada con ella en muchos casos y aun a veces se descubren anticipados vislumbres; pero se trata, en general, de un proceso de paso mucho más lento, de menor alcance y más temerosa manifestación pública. Es sintomático que, desde los momentos del despertar de una nueva mentalidad, los "novadores" insistan en que hay que dejar aparte de esta renovación de las ideas una serie de disciplinas; no lo es menos que Feijoo, que hoy vemos como incuestionable, clarísimo newtoniano, emplee hasta fecha muy avanzada expresiones francamente ambiguas; y, sobre todo, que ya en plena madurez de la época, Jovellanos, para descargar su conciencia, se vea obligado a declarar una y otra vez que su Informe sobre la Ley Agraria (en donde apenas si podría haber algún roce con intereses sociales y con el poder eclesiástico) es un texto que no corresponde a su propio pensamiento, sino que lo ha entregado francamente recortado. En carta a don José de Guevara Vasconcelos (1794), le hace la confidencia siguiente: "Pudiera, ciertamente, haber dicho más en cuanto a amortización, ma-

2 Lucienne Domergue, Censure et lumières dans l'Espagne de Charles III, Paris, 1982, p. 8.

${ }^{3}$ L. Domergue, Jovellanos à la Société Économique des Amis du Pays, Paris, 1971.

4 JOHN BURY en su obra clásica History of freedom of thought, $2^{\mathrm{a}}$ ed., London, 1952 , cap. V (que más bien hace la historia de la libertad de conciencia que la de la libertad de pensamiento, de mayor amplitud en su alcance) sostiene que en el siglo XVI -y aun en el XVIII- el auge que se advierte en la defensa de esa libertad viene, más que de argumentos sacados de los nuevos conocimientos científicos, de argumentos de carácter moral y teológico - o antiteológico- sobre el contenido de la revelación cristiana. 
yorazgos, contribuciones, etc.; pero Vm., que conoce cuánto hay que vencer para llegar en estos puntos a conseguir algo, hallará tal vez que he puesto el tiro muy adelante. No basta ver adónde se debe llegar; es preciso no perder de vista el punto de que se parte"5. Y con palabras de excusa semejantes, aludiendo a la diferencia - que, por tanto, hemos de considerar había de ser bastante pronunciada- entre lo que juzga puede decir dentro de una medida que se acepte por los demás y lo que él, de haber podido escribir libremente, hubiera sostenido, Jovellanos se dirige también a otra persona con la que está en continua comunicación -y en algunos casos, discusión-, el cónsul inglés Hardings (cuyo nombre castellaniza en muchos casos, para uso interno - quiero decir, en sus Diarios - y le llama Jardines); sin citarlo, le habla, pues, de su ya mencionado Informe y le hace esta advertencia:

éste en suma es mi sistema, aunque confieso que le hubiera acercado mucho más al buen término si hablase a mi nombre. Pero escribía a nombre de un cuerpo que entonces no hubiera adoptado mis ideas, que ahora no las aprobará sin dificultad, y cuya aprobación sin embargo es importante, no sólo para darles un peso de autoridad, sino porque sólo así podrán esperar la luz pública y alguna aceptación ${ }^{6}$.

Y más aún; cuando, en una parte de sus Diarios, correspondiente a 1795, Jovellanos recuerda el tema, anotará en esas páginas que después dirá con más claridad, esto es, con más sinceridad, cuál es su pensamiento en la materia y explicará " por qué no propuse la absoluta abolición de todo vínculo y especie de amortización, que creo necesaria, por qué puse alguna [limitación] a la libre extracción de granos, que creo justa, y otras cosas que pedían los presentes tiempos"7.

Me he entretenido en recoger estos testimonios de Jovellanos, porque creo que ellos confirman la tesis que en alguna otra ocasión he expuesto, de que nuestros ilustrados, o por lo menos buena parte de ellos (Meléndez Valdés, Cabarrús, Arroyal, Montengón, etc.), van en su pensamiento bastante más allá de lo que una rápida y somera lectura de sus obras nos permite entender; y de paso, esta comprobación nos ayuda a ir prevenidos, cuando nos enfrentamos con sus escritos, de que debemos leerlos buscando en muchos de ellos un doble plano, distinguiendo lo que, quizá sin darle demasiada relevancia, leemos a primera vista y aquello que descubrimos cuando nos preguntamos qué es lo que se quiere dar a entender (lo que, claro está, hemos de comprobar que concuerde con otros puntos del pensamiento del autor). Por ejemplo, si leemos con un poco más de cuidado en el Diario de Moratín que Bolonia podría ser república,

5 Gaspar Melchor de Jovellanos, BAE, 86, pp. 189-190.

${ }^{6}$ Epistolario, ed. Caso González, Barcelona, 1970, p. 92 (carta de mayo de 1794).

${ }^{7}$ G.M. Jovellanos, Diarios, BAE, 85, p. 317. Hace referencia a una carta de Meléndez con juicios elogiosos y con reparos al Informe sobre la ley Agraria (nota del 7 de agosto de 1794). 
no podemos quedarnos en que Moratín abogue por un cierto mejoramiento de los servicios municipales, sino que, tomando en cuenta su anticlericalismo y su alejamiento de la religión católica, y, por otra parte, su tibio monarquismo, lo que nos transmite es una cumplida declaración de la satisfacción con que vería y hasta la esperanza que tiene de que se produzca ese cambio en la ciudad. Ello supondría una disminución del dominio terrenal de los Papas (en el que Bolonia se hallaba comprendida) y la aparición de un régimen republicano que fortalecería el papel de la libertad, estimando una y otra cosa positivamente como premio a esa gran calidad ciudadana de la prestigiosa urbe italiana ${ }^{8}$. Cuando Arroyal, en una de sus Cartas económico-políticas, nos dice enérgicamente que la Monarquía española es como una casa vieja que hay que derribar y edificar de nuevo, es obvio que el autor no se conforma con parches de corto reformismo económico y administrativo, sino que él propondría una reforma de raíz, total, por tanto todo un programa político de renovación con un discernible rumor revolucionario ${ }^{9}$.

En estas condiciones precarias en que se mantenía la libertad política, de la que no cabe decir que informara el régimen de coexistencia de los españoles, pero tampoco que fuera olvidada por éstos, ni que dejaran incluso de esforzarse en su práctica, aunque fuera parcial y encubiertamente, cabe representarse la importancia que alcanzaba una de las libertades individuales integradas en el haz de la libertad política. Me refiero a la libertad de pensamiento, o mejor dicho, a la libertad de expresión del pensamiento, emitido oralmente o por escrito; libertad desdoblada y, consiguientemente, conjugada, en uno y otro caso, con la libertad de reunión y con la libertad de imprenta.

Podemos partir de que no vamos a encontrarnos con ninguna obra semejante a las que se producen en lengua inglesa, muy tempranamente. Pienso en el discurso de J. Milton, Areopagitica for the liberty of unlicensed printing, 164410; algo después, quizá con menos relieve literario, pero tal vez también con no menor eficacia polémica, en lengua francesa - como algunas páginas de Bayle. Es necesario llegar a los primeros años del siglo XIX, a la crisis de la invasión napoleónica, para que se encuentren en España publicados algunos escritos, algunos folletos, traducidos u originales, sobre la cuestión, al modo del que se hizo público

8 Carta a Juan Antonio Melón, desde Bolonia, 23 de julio de 1796, en el Epistolario, ed. R. Andioc, Madrid, 1973, p. 209. En carta al mismo, septiembre del año 1795, le preguntaba qué hacer y a dónde dirigir en España, desde Italia, un cajón de libros para que llegaran intactos a su destino, "sería menester - añade- que todo quedase claro y corriente, para evitar los peligros inseparables que rodean a todo el que quiere leer", p. 196

9 Véase mi artículo "Las tendencias de reforma política en el siglo xviII español", ROcc, 18 (1967), 53-82.

10 Existe una edición bilingüe (inglés-francés) de O. Lutaud, París, 1956, con un extenso estudio preliminar que constituye un aporte interesante para la comprensión de la historia de la libertad de expresión del pensamiento, en su primera fase. 
con el título de Cuatro verdades útiles a la Nación estractadas de algunos escritos españoles de Antillón, en 1810. A este vehemente defensor de la 'libertad de opinión" - nombre con que él y otros muchos la designan-, sus exigencias sobre la materia, presentadas ante la Junta Suprema Central Gobernadora del Reino, instalada en Sevilla, le costarían verse encarcelado por la misma Junta que abría las puertas del camino hacia las libertades constitucionale ${ }^{11}$. Pero escritores como el mencionado Antillón, o como Calvo de Rozas, Argüelles, Muñoz Torrero, Nicasio Gallego, J. B. Morales, Blanco White, etc., desbordan el marco de la mentalidad ilustrada y de ellos no me voy a ocupar ${ }^{12}$.

Lo cierto es, sin embargo, que desde los últimos lustros del siglo XVIII, en que un cambio de coyuntura anima tanto el mundo de la economía como el de la cultura, se descubre el interés por el tema de la libertad de pensar, se afirma enérgicamente en el terreno de la ciencia, pero no estoy enterado de que se lleve a cabo - lo que por otra parte era de esperar - ningún desarrollo doctrinal del mismo. Con mayor o menor amplitud y desplazando la cuestión a terrenos más amplios, aunque expresamente dejando por lo general algunos fuera - la religión, los actos del soberano, etc. - y, sobre todo, acentuando el tono polémico de la defensa de esa libertad, la cuestión de la libertad de expresión del pensamiento recorre todo el siglo XVIII. Sin embargo, los nombres más notables que, al cerrarse el período de la Ilustración e iniciarse la fase del primer constitucionalismo, participaron en la defensa de aquélla, veremos que se muestran con pocas ilusiones de llegar a un pleno reconocimiento legal de esa preciada libertad.

En España, sin embargo, por una serie de circunstancias que facilitaron durante una buena parte del siglo renacentista, la iniciación de unas transformaciones que promovieron el carácter abierto y expansivo de la sociedad - provocadas aquéllas por circunstancias económicas, experiencias geográficas, relaciones políticas, contactos con otros pueblos, asimilación o transmisión de elementos culturales de diverso origen, reunión bajo una instancia de poder de los grupos peninsulares más o menos diferenciados, conservación de un incuestionable nivel de pluralismo, etc. - , la mentalidad de las gentes estaba preparada para incorporar actitudes, cuya sedimentación constituía una preparación adecuada para servir de suelo sobre el que brotara la planta de la libertad

11 Sobre este personaje, geógrafo de cierto renombre en su tiempo y, durante la guerra antinapoleónica, luchador liberal en el campo de la política, puede verse el discurso de Pedro Beltrán y Rózpide en la Real Academia de la Historia, 1903. El folleto de Antillón contiene una selección de escritos de otros autores o anónimos. Su defensa de la libertad de opinión figura en la "Advertencia" que precede a los demás textos.

12 Quizá Calvo de Rozas fue el primero en hablar de "libertad de imprenta" y sobre todo de "prensa libre". Expone su programa, de tendencia radical, en un folleto, Aviso a los representantes de la nación española, Cádiz, 1813. Presentó en septiembre de 1809 una proposición ante las Cortes para el reconocimiento de dicha libertad. El 14 de octubre de 1810 se empezó a discutir el proyecto presentado por Argüelles. 
de pensamiento. Pienso, aunque no quiero dar a estas palabras más que el valor de una insinuación, que la sociedad española, al llegar el siglo XVIII y esparcirse por Europa nuevas formas de mentalidad, pudo haber ofrecido un terreno adecuado para el desenvolvimiento enriquecedor de esa libertad básica. Y añadiré que en mi opinión, si no fue así, ello se debió a que entre la época del Renacimiento y la de la Ilustración, el siglo del Barroco sometió a dura represión todas las energías de expansión y libertad — reducidas al simulacro de la gesticulación barroca- que hubieran podido fecundar las aspiraciones innovadoras. Se encargó de enunciar la ley de esa etapa represora del XVII un pleno representante de la misma, Calderón, en unos versos de El gran teatro del mundo a los que bien podríamos titular la "ley de represión del pensamiento". En ellos, un personaje, el "Buen genio", no acepta emprender la carrera cabalgando sobre el "Pensamiento", sino con una condición:

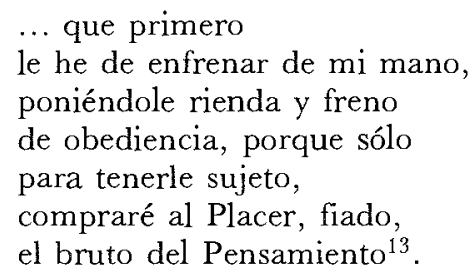

La sociedad tradicional, a través de la actitud general del Medievo, y haciendo oír todavía sus ecos en el XviII, había mantenido la dualidad de "opinión" y "razón", extremándola y cerrando ambos términos más de lo que se apreciaba en su origen aristotélico. Había hecho de la primera una manifestación caprichosa, descalificable del pensar; como mero producto del individuo, errónea. Y de la segunda una plena manifestación del depósito eterno de la verdad, alcanzada y formulada por el individuo, sin alterar en nada el legado con ella recibido. Comprobamos que, paralelamente, un giro radical se empieza a producir en el Renacimiento, desde fines del siglo xv, lo que en España va a dar muestras incuestionables del cambio. Citaremos, en muy apretado resumen, algunas de ellas y comprenderemos que su presencia a un mismo tiempo anunciaba la libertad promotora de todo el desenvolvimiento intelectual moderno.

En primer lugar la estimación de los valores positivos de la duda que, si por una parte, negativamente, aparta del error, por otra, hace aparecer la verdad, y si bien relativiza los caminos hacia la misma, los hace múltiples y permite que alguno se encuentre en la recta dirección. " $\mathrm{El}$ dudar ha sido en gran parte causa de saber la verdad", escribió el bachiller Alfonso de la Torre ${ }^{14}$. (La profesora Jacqueline Ferreras-Savoye,

13 Pedro Calderón de la barca, El gran teatro del mundo, ed. E. Frutos Cortés, Madrid, 1976, p. 150

14 ALFonso de la torre, Visión deleytable de filosofía, BAE, 36, p. 342. 
en su amplia investigación sobre la literatura de diálogos de género meditativo en la literatura del XVI, ha extraído varios pasajes semejantes) ${ }^{15}$. De este planteamiento que promueve la discusión (Carl Schmith vio en esto un carácter del burgués: la burguesía "discutidora'), se engendra tolerancia, la cual supone pluralidad de opiniones, discrepancia sobre valores constitutivos en el orden de la convivencia; término este de "tolerancia" que adquiere en el xvi cierta frecuencia y que en Furió Ceriol da lugar a una aceptación del libre examen, defendiendo la traducción y difusión de la Biblia en lengua vernácula (lo que dará lugar a la prohibición de su obra Bonomia, sive de libris sacris in vernaculum linguam convertendis, libro duo, por la Inquisición y a que ésta molestara todavía al clérigo Joaquín Lorenzo Villanueva, diputado después en las Cortes de Cádiz, por haber elogiado la obra de Furió). Un aspecto nuevo en la vida del siglo XvI, ligado a lo anterior, es el elogio de la novedad: el escultor Guillermo Doncel (1524), en el frente de uno de los escalones que suben de la primera a la segunda fila de poltronas del coro alto de la iglesia del Monasterio de San Marcos de León, escribió el gran tópico de la éooca, "omnia nova placet". Con ello se abre la vía a la crítica del hasta entonces "modelo" del saber de los antiguos. Aceptado durante siglos como intocable por la preceptiva de la "imitación", desde el XVI muchos lo echan abajo con la exaltación de la "invención" personal (Laguna, Sabuco, Huarte de San Juan, etc.), y aun de la creación original sacada libremente y gozosamente por el artista o escritor (Pérez de Oliva). No cabe duda de que la libre invención reclama muy de inmediato la libertad de pensamiento. De ahí que encienda la protesta contra el principio de autoridad, afirmando el derecho al pensamiento: gallardamente, lo reclama así ante la Inquisición Sánchez de las Brozas, afirmando ante el Tribunal su derecho a examinar y criticar las doctrinas, dejando aparte los dogmas de la fe. Esta actitud entraña ya un desplazamiento hacia el campo de la política, de la autoridad establecida, del orden social. Es Antonio López de Vega quien va a dar este paso francamente, entrado ya el siglo XVII, denunciando el "totalitarismo" oculto bajo el poder: la soberanía de los que mandan - sostiene acremente- "se ha extendido a querer subordinar también los entendimientos y a persuadirnos que no sólo los debemos obedecer y servir con los miembros, más aún con la razón, dando a todas sus determinaciones el mismo crédito que a las divinas" ${ }^{\prime 6}$. Con anterioridad, Furió Ceriol había sostenido un duro ataque contra quienes seguían esta línea de ominosa subordinación y llegaban a pretender que el Rey no podía errar. Afirmar lo contrario, como había hecho Furió, era tanto como reinvidicar el derecho a examinar y criticar los acuerdos

15 Véase su tesis doctoral presentada en la Universidad de Bordeaux, 1981, todavía inédita, cuyo título es Les dialogues espagnols au xvi siècle ou l'expression littéraire d'une nouvelle conscience. 86.

16 Antonio López de Vega, Paradoxas racionales, ed. E. Buceta, Madrid, 1935, p. 
y mandatos de la suprema potestad política; un elevado y peligroso nivel de libertad política, de libertad de pensamiento ${ }^{17}$.

Matizando y completando lo que antes he dicho, en el xvil esta corriente, en manifestaciones públicas, queda casi asfixiada; pero no del todo extinguida. Subsiste en forma de opinión sumergida de capas anónimas de población que hacen oír su rumor en revueltas, panfletos, pasquines (cuya defensa hizo Saavedra Fajardo, e hizo también Quevedo, no hay que olvidarlo). Y es así, aproximadamente desde los veinte últimos años del siglo xviI, que se vuelve a replantear la defensa de la libertad de pensamiento, en el curso de una serie de reivindicaciones que van de la ciencia y la filosofía a las instituciones y normas sociales, y - aunque siempre veladamente o, por lo menos, con cierta capa de disimulo- alcanzan a la Iglesia y a su legado religioso. Éste quedaba, en el Barroco, bien apartado del pueblo en su contenido espiritual, porque en España prácticamente fue ahogado por la manera de entenderse y aplicarse el Concilio de Trento.

Mantengo el término de "notas" al pasar a estudiar el siglo XVIII, porque aquí tan sólo me propongo ensartar una serie de textos, elegidos entre escritores de diversos géneros y sectores, para comprobar con datos concretos la presencia de esa línea doctrinal, con cuyo enunciado he comenzado estas páginas. Son pasajes breves y ocasionales, escritos, eso sí, con vehemencia, pero que no suponen un desarrollo teórico complejo. En ningún caso hacen alusión especial a la prensa periódica, ya que este último aspecto no aparece hasta empezado el siglo XIX.

Un escritor italiano ha sostenido que fue a través del nexo que unió el legado intelectual de Galileo con la ciencia de Newton como se produjo la corriente que en Italia, basándose en el primero de los grandes físicos, se iniciaría y tomaría auge: la defensa de la "libertas philosophandi', Esa línea de pensamiento, y la versión de la libertad intelectual que suscita, se ponían de manifiesto en un artículo de Paolo Frisi, aparecido en $I l$ caffé en $1765^{18}$. Yo creo, sin embargo, que mucho antes de esa fecha y a partir de otro origen, la "libertad de filosofar" - primera fórmula probablemente de una libertad de pensamiento definida como tal, aunque sea parcialmente- es de procedencia cartesiana y se anuncia bastante antes de que empiece el siglo xviII. Su línea ideológica queda coagulada, desde entonces, para toda la centuria ilustrada. Esa doble circunstancia se pone de manifiesto en el título mismo y en la dedicatoria a la República de Venecia que el judeo-español y cartesiano Isaac Cardoso hace en 1673 de su Philosophia libera. Y veremos en seguida la amplitud que el tema adquiere ${ }^{19}$.

17 Véase mi libro La oposición política bajo los Austrias, Barcelona, 1972.

18 V. Fer Rone, Scienza, natura, religione. Mondo newtoniano e cultura italiana nel primo Settecento, Napoli, 1982.

19 IsAaC Cardoso, Philosophia libera, Venecia, 1673. Es revelador el subtítulo "Opus non solum Medicis, et Philosophis sed omnium disciplinarum studiosos utillissimum". 
La investigadora que puso en claro los comienzos de la filosofía moderna en España, Olga Quiroz, hace este comentario, que debe tomarse en cuenta: "El concepto de libertad filosófica viene a traducirse en el de la libertad propia del físico investigador, limitado a observar directa y objetivamente la naturaleza, y razonar consecuentemente a sus observaciones, desligado de prejuicios de escuela y de toda clase de preocupaciones"'20. Libertad de filosofar quería decir, pues, liberación de todo género de prejuicios por parte del científico y pensador; rechazo de posiciones doctrinales, autoritariamente sostenidas en su tradición.

Bajo esa forma, todavía en 1687 - fecha de aparición de su decisiva Carta filosófica, médico-chymica-, el doctor Juan de Cabriada hace una reiterada defensa de la independencia del investigador frente a toda autoridad doctrinal, llamándola "libertad filosófica" o "libertad de discurrir" (lo que significa una ampliación de su campo), terminología que otros hacen suya, sin dejar de advertir sobre su procedencia en Cabriada ${ }^{21}$.

Con esto, los autores que figuran en el grupo de los "novadores", tanto a fines del XVII como en las primeras décadas del XVIII, quieren decir que el que estudie, investigue, reflexione sobre problemas de las ciencias naturales, ha de permanecer neutral o indiferente o desapasionado, lo que equivale a "despreocupado". Tanto el falso Avendaño, como el doctor Martín Martínez, o el doctor Mateo Zapata, etc., se expresan en términos equivalentes. El último de los citados, cuya obra póstuma, Ocaso de las formas aristotélicas, se publica ya en fecha avanzada -1745-, se mantiene todavía en estos límites: "defienden los católicos Atomistas sus opiniones, sin que la pasión de este o de otro filósofo los ciegue, ni los arrastre la vil pesada cadena de la antigua esclavitud", de modo que, dejando aparte la pureza de la religión, buscan "con libertad filosófica la verdad o lo que parece más allegado a la razón'”22. Desde el momento en que no es exigencia inexorable para legitimar la libertad científica o filosófica la comprobación de que ésta haya alcanzado la instancia absoluta de la verdad, sino que basta con haber conseguido aproximarse a lo que parece razonable, no cabe duda de que se revela un nivel nuevo, mucho más desprendido de la autoridad de la tradición, mucho más cercano de una apelación a la libertad. Y así declaraba Avendaño que "en puntos naturales han apellidado libertad"23.

En los comienzos del siglo XVIII, el gran personaje es sin duda el

20 Olga Quiroz-Martínez, La introducción de la filosofía moderna en España, México, 1949 , p. 56.

21 JOSÉ MARía LóPez-Piñero, Introducción a la ciencia moderna en España, Barcelona, 1969, pp. 101 ss. Cabriada emplea todavía la multisecular imagen de "enanos en hombros de gigantes" " para dar una versión "porvenirista". Véase el estudio del mismo LÓPEZ-PIÑERO, "La Carta filosófica, médico-chymica (1687) de Juan de Cabriada, punto de partida de la medicina moderna en España”, Asclepio, 1965, núm. 17.

22 Quiroz-Martínez, op. cit., p. 159.

23 Loc. cit. Allí se recogen varias opiniones semejantes. 
P. Vicente Tosca, oratoriano, que en Valencia llevó a cabo un combate de gran trascendencia en el terreno científico, de manera que, aunque no fue universitario, alcanzó en la Universidad gran influencia, y aun más allá de la Universidad, sobre todo en tierras de la Corona de Aragón y también del resto de España. Lo elogia Feijoo, y recordemos lo que de él dijo el P. Isla, flagelador tan ingenioso de farsantes del saber: debido al elogiable empeño del P. Tosca, "en los reinos de Valencia y de Aragón se perdió del todo el miedo al nombre de Aristóteles" y en virtud de ello "en las Universidades de aquellos dos reinos" se ha alcanzado tanta y tan cumplida noticia del moderno saber de la naturaleza que se puede hablar en ellas de estas materias con tanta autoridad como en las Academias de Berlín o de París ${ }^{24}$. Era justo que Gregorio Mayans, en carta al ministro José Patiño (1734), y más tarde en cabeza del Compendium philosophicum de Tosca, reeditado por aquél en 1754 (la primera edición era de 1721), le atribuyera haber introducido en la Universidad de Valencia "la libertad de filosofar"'25. Se trataba de la libertad del pensador - del científico, del filósofo- para, entre tantas ideas, poder elegir unas u otras, sin más objetivo que el de seguir libremente la verdad. Ya no habrá que mantenerse en la balumba de errores y aun de disparates que componían el acervo de la filosofía recibida de los pretendidos maestros antiguos. Para Tosca, francamente, no. Aunque se expresara con cierto disimulo, quedaba claro que lo que él reivindicaba era tanto como pensar por su cuenta, y, en consecuencia, innovar, "intentando injertar renuevos a lo viejo y mezclar lo antiguo a lo nuevo, de modo que de este injerto se produzcan abundantes frutos, para utilidad y placer de los lectores"26. Mayans, en la biografía del P. Tosca que publicó al frente de la edición mencionada del Compemdium philosophicum, cuenta que un día se acercó a su admirado maestro, hallándose éste trabajando, y le preguntó a quién se proponía seguir en sus doctrinas, a lo que Tosca, al tiempo que señalaba con el dedo una estatuilla que se hallaba en su cuarto y representaba a la "libertad filosofante", le contestó, "a ésta"27. Tosca, en otra de sus obras, anterior a la que he citado, el Compendio matemático (1707), como han demostrado los especialistas, sostiene abiertamente las tesis, conexas entre sí, copernicana, galileana, newtoniana, acerca del movimiento, dando a sus palabras un carácter polémico que implica un dehberado uso de la libertad científica ${ }^{28}$. Esta actitud tan abierta y renovadora tuvo su re-

24 José F. DE IsLA, Historia del famoso predicador fray Gerundio Campazas, ed. R.P. Sebold, Madrid, 1961, t. 2, p. 108.

25 Citado por Antonio Mestre en Historia, fueros y actitudes políticas. Mayans y la historiografía de! siglo xviii, Valencia, 1970, p. 57.

26 Véase QUiroz -Martínez, op. cit., capítulos III-i y VI.

27 Gregorio Mayans, Vita Thomae Vicentii Toscae, que precede a la edición de la obra de Tosca, Compendium philosophicum, Valencia, 1754; véase también Ibid., nota 26 , p. 49.

28 Cf. A. Mestre, Ilustración y reforma de la Iglesia. Pensamiento político-religioso de Ma- 
percusión. Es muy posible que influyera en Feijoo, entre cuyas lecturas no es fácil hallar otras fuentes desde las que le llegara el pensamiento de Copérnico y Newton (los cuales, en la Península tropezaban con la barrera inquisitorial, de ellos el segundo porque iba vinculado al primero). El mayor obstáculo era Copérnico, a comienzos del xviII, al cual Tosca explícitamente acepta. Y su admirador Mayans, cuando, años más tarde, redacte por encargo del gobierno de Carlos III el plan de estudios en las Universidades del Reino, establecerá que el profesor de Astronomía pueda optar en sus explicaciones entre las que llama "hipótesis copernicana o semicopernicana"29. Esto no era, exactamente, tanto como la manifestación de la libertad de pensar; pero se había llegado a su misma puerta.

Detengámonos un momento en este plano de la cuestión. Mayans, joven estudiante, proclama desde Salamanca, en uno de sus primeros escritos: "Ego, cum veritate, adversus omnes". Esto, sin duda, tampoco es de suyo una afirmación de pensamiento libre. Tiene demasiado peso en esa apelación la resonancia de la creencia en una verdad absoluta y única, para que veamos en su afirmación una muestra de mentalidad ilustrada: lo propio de ésta es afirmar la vía libre para llegar a aquélla $a^{30}$. Y esto es lo que, poco más de diez años después, Mayans va a reclamar en carta al ministro Patiño: la filosofía es una ciencia que, si demanda larga meditación y experiencia (es significativo el uso de esta palabra, hablando de filosofía), necesita sobre todo de libertad en profesarla; no verse obligado el filósofo a seguir alguna escuela por imposición ajena, y por eso pide la "libertad filosófica"; la carta es de 1734".

Mayans nos da más tarde, llevado de su enérgico carácter presto al enfado, un testimonio interesante de la irritación que produce el escaso margen de libertad conseguido en la esfera que aquí nos ocupa. En una carta al nuncio E. Enríquez (1751), refiriéndose a las trabas con que se tropieza para combatir las ignorantes creencias en la patraña de los "falsos cronicones" o de los "plomos del Sacromonte" o la insostenible leyenda de la venida del apóstol Santiago a España, campañas en las que tan irritable se mostró, escribe: "Y así este combate toca a los extranjeros hasta que, habiendo menos ignorancia y más libertad, puedan los españoles escribir lo que sienten sobre puntos puramente histó-

yans, Valencia, 1968, pp. 46 ss., donde señala el interés de Mayans por los físicos modernos, por influencia de Tosca; y QUIROZ-MARTínez, op. cit., cap. VII.

$29 \mathrm{G}$. Mayans, Idea del nuevo método que se puede practicar en la enseñanza de las Universidades de España (1767), texto íntegro publicado en la obra de MARIANo y José Luis PESET, Gregorio Mayans y la reforma universitaria, Valencia, 1975.

$30 \mathrm{Cf}$. A. Mestre, Ilustración..., ed. cit., p. 44. El planteamiento de la libertad de pensamiento desde el punto de vista de una verdad absoluta, no de la duda y la discusión, se observa en un pasaje de la Idea. . ., "No se haga profesión de seguir a Platón ni a Aristóteles ni a cualquier otro filósofo antiguo o moderno, sino sígase solamente la verdad", p. 221.

31 Espistolario español, BAE, 2, p. 160. 
ricos que no tienen conexión con la religión". Sin embargo, no toda la carga polémica contra estos y otros errores la han de llevar desde fuera, y en 1753, añade: "Lo que importa es que los españoles que no podemos hablar en público en este asunto, indirectamente procuremos manifestar la falsedad de muchas piezas sobre que se apoya, porque de esta manera insensiblemente, por claras y evidentes consecuencias, se inferirá ser una pura ficción uno y otro"'32.

Estas dificultades con que se encuentra cargan de acritud muchos pasajes de Mayans, pero a la vez le imponen atenerse a una corta medida en sus reivindicaciones. De ordinario, se refieren éstas a manifestaciones de credulidad en el terreno de la religión, que perjudican a esta misma, así como a la falta de sentido crítico y de libertad para expresar esa crítica, en el terreno del derecho, de la historiografía, de la literatura, de la lengua. En estos campos, su criterio es menos abierto, como cuando abandona la amistad del doctor Piquer, al empeñarse éste en llamar - no sin parte de razón - una obra suya Física moderna, mientras que aquél considera que ese título es una ofensa a los sabios antiguos, de los que -invidencia notable de Mayans- la física de la época no se apartaba como para pretender presentarse diferente.

Una batalla semejante era la que enfrentaba a Feijoo con los conservadores de su tiempo. Feijoo lleva su atención y su ataque más al terreno de cuestiones naturales, sociales, políticas, y llega a contemplar la vertiente política de la libertad y concretamente de la libertad de pensamiento - contra lo que tan equivocadamente sostuviera A. Millares. Pero, eso sí, sus limitaciones, sus temores, sus disimulos son del mismo género $\mathrm{y}$, en ocasiones, le llevan a expresiones ambiguas (son innegables sus ambigüedades sobre Newton, puestas en claro, primero por A. Ardao, y después por J. D. Browning) ${ }^{33}$; en este sentido, a pesar de todo resulta probado su newtonianismo. A veces nos encontramos con patentes contradicciones en sus textos. $\mathrm{Y}$ con todo, su nombre representa un hito en la libertad de pensar.

He aquí dos declaraciones de Feijoo que reflejan ese último titubeo en que se unen su impulso polémico y su prudencia temerosa - no olvidemos que la Inquisición alguna vez le ha mostrado sus garras. En su discurso "Demoníacos" pide: "no se me considere como un atrevido ciudadano de la república literaria que, satisfecho de sus propias fuerzas, y usando de ellas, quiere reformar su gobierno"; en cambio, en uno de sus discursos más interesantes, que lleva por título "Lo que sobra y lo que falta en la física", se define inversamente: "así yo, ciudadano libre de la república literaria, ni esclavo de Aristóteles ni aliado de sus enemigos, escucharé siempre, con preferencia a toda autoridad

32 A. Mestre, op. cit., véase supra nota 30, pp. 193 y 196.

33 Véase Arturo Ardao, La filosofía polémica de Feijoo, Buenos Aires, 1962; y J.D. Brown1NG, "Yo hablo como newtoniano": el P. Feijoo y el newtonianismo", en II Simposio sobre el P. Feijoo y su siglo, Oviedo, 1981, t. 1, pp. 221-230. 
privada, lo que me dictaren la experiencia y la razón" "34. Rechazando duramente la introducción de opiniones nuevas a que lleva el libre examen racional de la propia observación de las cosas, Feijoo sostendrá, sin embargo, en "Guerras filosóficas" 35: "La novedad en las cosas puramente filosóficas no es culpable. Nadie hasta ahora fijó ni pudo fijar columnas con la inscripción Non plus ultra en las ciencias naturales... Donde hay gran riesgo de errar, excluir toda novedad es en cierta manera pensar de parte del error". Proclama - y esto encierra toda una afirmación de libertad de pensamiento- que "es regla segura que se debe preferir la razón a la autoridad" 36 , y aquí "razón" significa, no la razón absoluta de la palabra de Dios, según tantos teólogos, ni la razón del príncipe (según tantos políticos del absolutismo, hasta un tardío Donoso Cortés), sino la razón individual del observador. Y esto para él es ya un nivel alcanzado: los filósofos experimentales abrieron brecha en la doctrina aristotélica y, vencida la antigua preocupación, ha quedado "hecha país libre la filosofía"; el autor, en el discurso sobre el estado de la física que acabo de citar, exalta la "libertad de filosofar'. Se comprende que él desatara, no ya enemistades personales por ataques o diferencias de este mismo carácter, sino toda una actitud general de condenación en la que se le imputan descalificaciones que la credulidad reaccionaria todavía hoy emplea: "hereje" y "antiespañol". Recordemos los zafios versos de un familiar de la Inquisición contra él, que Nlesonero Romanos dice haberle escuchado de muchacho en casa de sus padres (el tal sujeto presumía de hábil improvisador):

$$
\begin{aligned}
& \text { El que leyere a Frayjó, } \\
& \text { el que traduce el francés, } \\
& \text { y el que gasta redingote... } \\
& \text { Hugonote! } !^{37}
\end{aligned}
$$

En otra ocasión, he recogido testimonios que señalan por el contrario la deuda grande contraída con Feijoo por el público que, con afán de liberarse mentalmente, lo leía. Recogeré aquí como muestra las palabras de Blanco White en sus Cartas de España: "con la influencia de su obra: de repente había aprendido a razonar, a argüir, a dudar". Sin embargo, Feijoo, con más atrevimiento que algunos en su libre crítica (hay que ver la significación mucho más comprometida que esta palabra tiene en él de lo que ofrece en el P. Flórez o en Jacinto Segura) ${ }^{38}$

34 Benito Jerónimo Feijoo, Teatro crítico universal, t. 8, en donde figura una mención de Newton, con pleno acuerdo, y t. 7, discurso XIII, p. 324.

$35 \mathrm{Ibid}$., t. 2, discurso $1^{\circ}$, p. 12

36 B.J. FeIjoo, Cartas eruditas, t. 2, carta 18, "De la crítica", pp. 245 y 255; y Teatro crítico. ., t. 7 , p. 322 .

37 Citado por Iris M. Zavala en ese texto. Se inserta en el tomo 5 de las Obras completas de Ramón Mesonero Romanos, Madrid, 1967, BAE, 203, p. 8.

38 De FLórez me refiero a su obra Clave historial, Madrid, 1786; y de JACINTO Segura a su Norte crítico, 1783. 
o con más comedimiento que otros posteriores en unos años (Arroyal, Marchena, etc.), conserva siempre esas ambigüedades, reservas, limitaciones y aun caídas, que más de una vez se han señalado.

Una actitud de desconfianza - aparte de cuestiones personaleshizo a Mayans y también a Feijoo abandonar la Corte. Uno de los primeros en escapar de ella para preservar su independencia intelectual fue el Deán Martí. Éste se dedicó a cuestiones críticas, sí, pero de filología latina, de literatura, que aun así molestaban a la opinión tradicional en medios académicos de las Universidades peninsulares. El Deán Martí escribe al arcediano Francisco de Almeida (1736): "Siempre he practicado el retiro y recogimiento, y más en este país, en donde el saber algo es sambenito; el manifestarlo, escarnio; el ejecutarlo, vilipendio; y pues no hay cosa más despreciable entre mis paisanos que el saber, escogí un método de vivir, en el que profesar las letras me sirviera sólo de satisfacción propia"39. Por su parte, Mayans siguió luchando dirigiéndose a un público de sabios (entendamos, humanistas); Feijoo, con más amplia proyección, para un público dado a cuestiones físicas, naturales, médicas, etc., mucho más numeroso. Pero siempre en los términos circunspectos a que se veían forzados por el entorno. Atendiendo a esto, incluso el P. Isla - sin que ello le librara del choque con la represión político-eclesiástica- se veía limitado en su desenvuelta ironía y escribía protestando de aquellos que, "aprovechándose de la libertad de conciencia para filosofar que se han tomado, especialmente en este siglo, casi todas las naciones", se han entregado en la reflexión filosófica a una nueva fantasía ${ }^{40}$.

No vayamos a pensar que ésta era una situación peculiar de España, a diferencia radicalmente de lo que se veía en otras partes, porque ello sería falsear la situación de la época. Newton había escrito - recuerda N. Hampson- "si en no importa qué momento una cuestión cualquiera surge en contradicción con las tesis [cristianas], debemos desconfiar de la filosofía, de los vanos engaños y antinomias de la que falsamente llamamos la ciencia y atenernos al Antiguo Testamento"41. En sus Essays, publicados en 1767, D. Hume considera condenable la actitud de aquel que sostenía una opinión científica, que, por verdadera que fuere, "mueva a costumbres peligrosas y perniciosas" 42 . ¿Acaso no tiene sus propios frenos y límites el propio Voltaire? Por lo pronto los tiene hasta cuando protesta, incluso, de la manipulación de las conciencias, y en otros casos, se queda limitado a unas áreas, pero evita cuidadosamente extenderse a otras, por ejemplo, a la crítica de la autoridad política. Aun

39 Epistolario español, $B A E, 62$, p. 179.

40 J.F. IsLA, Historia del famoso predicador..., ed. cit., t. 2, p. 81.

41 Norman Hampson, The Enlightenment, London, 1968.

42 Citado por C.L. Becker, La ciudad de Dios del siglo xviii, trad. de J. Carner, México, 1943, p. 48. Sobre el fondo del pensamiento que en Hume apoya el interés por la acción práctica y la vida cotidiana, véase J. DE SALAS ORTUETA, El conocimiento del mundo externo y el problema crítico en Leibniz y Hume, ts. 2-4, pp. 139 ss. 
cuando pueda parecer que también se opone al poder político, esto último no va más allá de alusiones lejanas y personales. Su combate va siempre contra la superstición religiosa, como ha sostenido Pomeau, y aun ésta se nos aparece cada vez más matizada ${ }^{43}$. Voltaire no piensa que esos frutos de una posible libertad de conciencia y de pensamiento hayan de ser de universal disfrute, sino que se deben distribuir según una graduación que siga el orden jerárquico de la sociedad estamental. De ahí, su pregunta en 1756: "Jusqu'à quel point doit-on tromper le peuple?"

Esta pregunta suscitó un notable incidente en el mundo de las " $\mathrm{Lu}$ mières'. En 1777, d'Alembert se dirigió al rey Federico II de Prusia sugiriéndole propusiera a la Academia de Berlín la convocatoria de un concurso sobre el tema "Est-il utile de tromper le peuple?" El asunto ha sido estudiado por Werner Krauss (en una monografía aparecida en 1966). Por él sabemos que el Rey se dirigió en tal sentido a la Academia, que ésta cambió la cuestión dándole un enunciado muy abstruso, que d'Alembert volvió a insistir y que, por orden del Rey, aquélla lo sustituyó por un enunciado muy sencillo y muy próximo al propuesto. Krauss nos dice que algo más de la mitad de las respuestas recibidas negaban esa utilidad y poco menos de la mitad la afirmaban. El premio se dio a una respuesta en francés, en esta segunda línea, cuyo autor era Frédéric Castillon, compartido con la de un alemán, R.Z. Becker, que denfendía lo contrario. En general, la utilidad de no mantener al pueblo en el engaño se refería nada más en este caso a la cuestión religiosa. En Alemania, el poder de la lglesia luterana no era grande y aun así los reyes tenían interés en eliminarlo, para que resultara acrecentado el poder político. En las respuestas francesas también predomina este aspecto y las referencias al orden civil son mínimas ${ }^{44}$. Coincidiendo con esto observamos que el fundamental escrito sobre el tema de Kant (1784) tiene el mismo sentido: ilustración, para él, es liberación de toda tutela intelectual en la esfera de la religión, de manera que es a ésta a la que se refiere su famosa consigna, "Sapere aude" -en el mismo escrito defiende al poder real, sin tocar un ápice en él ${ }^{45}$. Algo muy parecido se podría decir de la frase de Voltaire que se adelantó a la citada: “Osez penser par vous-même""46.

Si en 1765 la Asamblea del Clero francés condenó las obras de la mayoría de los filosófos y condenaciones semejantes se repitieron aun

43 René Pomeau, La religión de Voltaire, Paris, 1974.

44 Werner Krauss, Est-il utile de tromper le peuple?, Berlin, 1966.

45 Véase I. Kant, “Qué es la Ilustración?", en su Filosofía de la Historia, trad. de E. Imaz, México, 1941, pp. 25 ss. Kant añade: "Mediante una revolución acaso se logre derrocar el despotismo personal y acabar con la opresión económica o política, pero nunca se consigue la verdadera reforma de la manera de pensar, sino que nuevos prejuicios, en lugar de los antiguos, servirán de riendas para conducir el gran tropel", pp. 27-28; por tanto, en el fondo todo quedará igual. Recordemos que Diderot definía la Enciclopedia como "une façon de penser".

46 En su Dictionnaire philosophique. 
en otras fechas; si Diderot, en sentido contrario, ejerciendo un puesto de censor por encargo del gobierno francés, pidió la prohibición de la obra de Palissot de Montenoy, Le satirique, porque se manifestaba contra las ideas de los filósofos; si Rousseau en Le contrat social pedía la formulación de "une profession de foi purement civile", cuyos artículos correspondía fijar al soberano, y al que no creyese en ella se le podía desterrar del Estado, todo ello y muchos datos más demuestran que en Europa, en el tercer cuarto del siglo XviII se está todavía lejos de aceptar la libertad de pensamiento y menos de ejercerla públicamente, salvo en el caso de algunos críticos arriesgados. En España es, sin duda, más grave la situación, son más enérgicas las fuerzas que se oponen a esa libertad — quizá más que a ninguna otra-, fuerzas concentradas en torno a una Iglesia política y de duro carácter disciplinario en lo religioso, y se parte de un desarrollo de las bases intelectuales que la crisis del siglo barroco ha dejado en posición muy endeble.

En España es más corto el radio de la pretensión, ordinariamente se deja de lado el núcleo resistente más poderoso - la alianza de rey e Iglesia, que el llamado "jansenismo" o regalismo no logra quebran" tar cuando llega su momento crítico- y el campo investigado por la crítica es mucho más reducido. Sin embargo, en torno a 1750 , más exactamente desde unos quince años antes, la aspiración al logro de esa libertad está lanzada, y aunque lo conseguido sea poco y se insista en la necesidad de disimularlo, los testimonios a favor de esa libertad ya no cesan y se descubre fácilmente que existe, a pesar de todo, una conciencia de que se gana terreno.

Iris Zavala ha hecho una observación, que debe ser tornada en cuenta en sus dos aspectos. En primer lugar, estima que la libertad intelectual es la única que pretenden los ilustrados españoles desde Feijoo a Meléndez Valdés, desde Cadalso a Jovellanos, y no olvidemos que bastantes más, como vamos a seguir viendo. En segundo lugar, que todos los escritores aceptan limitaciones necesarias para el más correcto desarro llo de la vida pública, en lo que - según la autora mencionada- coinciden en buena medida con los "libertinos" que les preceden ${ }^{47}$. Creo que, aceptando estas dos afirmaciones, hay que introducir algún matiz, al referirnos a escritores de fecha más reciente. En primer lugar, el carácter amplio - y hasta no demasiado perfilado- de la noción de filosofía y aun de ciencia, cuando se habla de libertad filosófica o cientifica, en la que se incluyen nociones prácticas muy lejanas de lo que hoy llamamos filosofía (por ejemplo, si es más conveniente arar con bueyes que con mulas). Ello quiere decir que la libertad comercial, la libertad de trabajo, la libertad de conciencia, la libertad personal, etc., están comprendidas en aquélla. De ahí que los economistas, entre otros, destaquen en la defensa de la libertad de imprenta. Y en cuanto a los lími-

47 Iris m. Zavala, Clandestinidad y libertinaje erudito en los albores del siglo xizî, Ariel, Madrid, 1978, pp. 134-135. 
tes que explícitamente se aceptan, tanto en lo relativo al gobierno político como a la religión, corresponden, a mi modo de ver, a las nociones burguesas de decoro y de orden - nadie es menos revolucionario, en la esfera de la vida púbiica, que el burgués, antes de que despierte su conciencia de otros problemas a partir de 1789 . Volvamos a referirnos a Kant que, hacia el final de la época aquí considerada, define en general la situación de Europa, salvo casos individuales de pensadores que han roto los vínculos que traban todavía la sociedad:

sí nos preguntamos ahora: ¿es que vivimos en una época ilustrada?, la respuesta será no; pero sí en una época de ilustración. Falta todavía mucho para que, tal como están las cosas y considerados los hombres en conjunto, se hallen en situación, ni tan siquiera en disposición de servirse con seguridad y provecho de su propia razón en materia de religión ${ }^{48}$.

Y si esto era así, prácticamente, en toda Europa, lo era en mucha menor medida que en España.

El esfuerzo de liberación había podido ser mucho mayor en Inglaterra y en Francia. También en Prusia era mucho más avanzada la penetración del espíritu crítico en la esfera de la religión que entre nosotros. Sin embargo, quizá en España se lograban reducir las barreras en la libertad personal y en la férrea compartimentación estamental a fines del siglo XVIII, por lo menos relativamente (de otra manera, no hubiera sido posible que se diera la guerra por la libertad que fue en el fondo la guerra antinapoleónica para la mayor parte del país).

Veamos algunos testimonos en la segunda mitad de siglo. El escritor de temas económicos Romá y Rosell (1768) sostiene que la "liber" tad de escribir" es necesaria para que se difundan por el país los conocimientos políticos; pero advierte que el gobierno ha de mantenerla en sus convenientes límites ${ }^{49}$. El abate Gándara juzga que hay un verdadero abuso en prohibir cualquier discurso, con la mayor facilidad, cuando no coincide con las ideas del que manda:

El discurrir es país libre... el impedir con exceso esta libertad natural es causa de grandes atrasos literarios. Los hombres grandes que podrían ilustrarnos, como en las demás naciones, todos se abstienen de escribir, temerosos de la facilidad de las prohibiciones, y éste es un medio de tener la nación a oscuras, proteger la ignorancia, fundar el idiotismo y hacer que los hombres no se iluminen un día más que otro. La decadencia de nuestra ilustración procede en mucha parte de este principio.

Quizá sea ésta una de las defensas más amplias, pero aun así, no falta al final la llamada a la obligada cortapisa. Los términos en que se ex-

48 I. KANT, op. cit., p. 34.

49 Romá Y Rosell, Señales de la felicidad de España y medios de hacerlas eficaces, Madrid, 1768, eñ el prólogo. 
presa Gándara penetran en la esfera de la política, cuando propone un amplísimo cuadro de materias en las que aquella libertad debe ser reconocida:

se dejará más libertad a los escritores, para que discurriendo, escribiendo, impugnando y criticando juiciosa y cortésmente, se aclaren y purifiquen y actifiquen las ideas científicas, los puntos históricos, las ciencias naturales, las materias opinales, los derechos de regalía, los artículos jurisdiccionales, las disputas legales, las controversias eclesiásticas, las cuestiones morales, los discursos políticos, los juicios críticos y, en fin, todas aquellas especies que pertenecen al raciocinio y son independientes del $\operatorname{dogma}{ }^{50}$.

En fechas bastante más tardías, Forner no va más allá de afirmar que "algo influye en los progresos de la literatura la sabia libertad que, sin permitir los precipicios del entendimiento, le deja esparcirse abiertamente" 51 . Pero no se puede dejar de tener en cuenta que "si por libertad de perar se quiere dar a entender la libertad de enseñar y publicar cada uno lo que se le antoje, puede la potestad suprema modificar también esa libertad y dirijirla del modo que le parezca más conducente para que no dañe y para que sea útil" 52 . No cabe duda de que es estrecha la franja de permisión que reconoce Forner, a pesar de su indudable carácter de ilustrado y su posición avanzada, por ejemplo en lo relativo a la estructura estamental ${ }^{53}$, condición de ilustrado que le atribuí al ocuparme de él ${ }^{54}$ y que François Lopez ha dejado bien aclarada ${ }^{55}$.

En esos cincuenta años de que hablo no encontraremos casos en que se muestre un abierto y avanzado nivel de revindicación y menos de ejercicio de la libertad política ni de la libertad de pensamiento. Se la desea, por algunos fervientemente; se la estima necesaria para el adelanto de la ciencia y de la educación ciudadana, de las artes y de las letras; pero se acaba admitiendo que no es posible todavía ponerla en aplicación. Es interesante comprobar a lo largo de esa etapa la coincidencia de tres testimonios de personajes muy dispares que denuncian, junto al mismo afán, la misma lamentación por lo mucho que se carece

50 Miguel Antonio de la Gándara, Apuntes sobre el bien y el mal de España, obra escrita por orden del rey Carlos III, y no publicada hasta la edición de Valencia, 1811 Véase sobre este autor la exposición y comentario que hace ANTONio ElORZA, La ideología liberal de la Ilustración española, Madrid, 1970, pp. 44 ss.

51 JuAn PABLo Forner, Oración apologética por España y su mérito literario (1786), Madrid, 1956 , p. 129.

52 J.P. Forner, Exequias de la lengua castellana, ed. Sainz Rodríguez, Madrid, 1967; y véase infra nota 53 .

53 J.P. ForNer, Informe fiscal en el expediente de la Universidad de Salamanca, ed. François Lopez, Barcelona, 1973, THM, pp. 192 y 212-216.

54 Véase mi artículo "El sentimiento de nación en el siglo xvir: la obra de Forner', $L T, 1967$, núm. 57, 25-56.

55 François Lopez, Juan Pablo Forner et la crise de la conscience espagnole au xviii ${ }^{\mathrm{e}}$ siècle, Bordeaux, 1976. 
todavía de tal libertad. Citaré en primer lugar la carta del erudito A.M. Burriel a Mayans (1750):

Es evidente y cierto que hoy sin mucho peligro no puede decirse desnudamente la verdad y vea Vmd. aquí lo que justifica a Flórez. Con todo eso creo que siglo y medio ha no ha habido para poderla decir disposiciones como las que hay ahora. Yo veo que la mayor parte de la gente alta y baja se va despreocupando y que se deshace la niebla del miedo y superstición. La lástima es que, por haber muy pocos que en cada caso sepan lo que es verdad, veo que muchos van pasando a los extremos contrarios y algunos desenfrenadamente. Paréceme que si hubiera quien hable sólidamente y con juicio, parando en el medio, sería bien recibido ${ }^{56}$.

El culto y libre, pero a la vez prudente, Moratín, en carta a Forner (23 de marzo 1787) se lamenta:

la edad en que vivimos nos es muy poco favorable; si vamos con la corriente y hablamos el lenguaje de los crédulos, nos burlan los extrangeros y aun dentro de casa hallaremos quien nos tenga por tontos; y si tratamos de disipar errores funestos al que no sabe, la Santa y General Inquisición nos aplicará los remedios que acostumbra ${ }^{57}$.

Y a su vez el severo Jovellanos, que por dentro va mucho más adelante en alguna ocasión de lo que deja ver y hacia fuera se mantiene cauto y receloso, escribe a $R$. de Floranes (julio, 1800), después de su fracasada gestión ministerial: "muchas otras ezperiencias me han convencido que la época presente, si buena para meditar y escribir, no lo es todavía para publicar" 58 .

Unos años antes, Jovellanos había sido más optimista. En su Elogio de Carlos III. (1788) asegura que con la libertad de circulación de las ideas se alcanza y propaga el conocimiento de los principios de la economía civil, y en posesión de ellos "todo se examina, todo se mejora según estos principios; y en la agitación de tan importantes discusiones, la luz se difunde, ilumina todos los cuerpos políticos del reino, se deriva a todas las clases y prepara los caminos a una reforma general" 59 . Con la terminología del primer momento, que nos es tan conocida, Jovellanos proclama que con el rey desaparecido se ha dado entrada a la "libertad de filosofar" 60 y piensa que, frente a la ignorancia y al sectarismo eclesiástico, con ella llegará "un tesoro de conocimientos filosóficos que circulan ya en los ánimos de nuestra juventud y empiezan a restablecer

56 Cf. A. Mestre, Despotismo e Ilustración en España, Barcelona, 1976, pp. 98 y 140; y su art. "Historia. . .", en Ilustración. . ., ed. cit., p. 209.

57 Leandro Fernández de Mora'tín, Obras póstumas, Madrid, 1867, t. 2, p. 79.

58 G.M. DE Jovellanos, Epistolario, BAE, 81, p. 233.

59 G.M. De Jovellanos, Elogio de Carlos III, en Obras en prosa, ed. Caso González, Madrid, 1969, p. 189.

60 Ibid., p. 183. 
el imperio de la razón" 61 . Jovellanos, recordémoslo de paso, es un entusiasta del papel que a los jóvenes corresponde en la difusión de la Ilustración, su libertad intelectual, la aplicación de sus conocimientos científicos, la convivencia conforme a una educación que inspira la filosofía. Por eso, Jovellanos, en sus Bases para la formación de un plan general de instrucción pública, sostendrá que "la libertad de opinar, escribir e imprimir se debe mirar como absolutamente necesaria para el progreso de las ciencias y para la instrucción de las naciones'"62. Temeroso y cauto, Jovellanos no sólo advierte, como hemos visto, que no se está ya en época de practicar esa libertad, a pesar de lo dicho, sino que además recomienda se concilie la afirmación de la misma con los graves peligros que entraña. Sin embargo, Jovellanos, a solas, en la intimidad de la correspondencia con algún amigo, cuando escribe para sí o para una próxima posteridad, se manifiesta siempre por la libertad. Y así, en sus Diarios, en anotación de marzo de 1796, dejará escrito que se ocupa en traducir el discurso de Boissy d'Auglas a favor de la libertad de prensa ${ }^{63}$.

Una actitud semejante se encuentra en otro escritor político, muy próximo a Jovellanos, a quien éste intentó visitar en su viaje por Guipúzcoa, Valentín de Foronda. Cónsul en Pennsylvania, amigo de Jefferson, regresó a la Península cuando la invasión napoleónica y fue de los primeros críticos del proyecto de la que sería Constitución de 1812. Pero veinte años antes, en el Espíritu de los mejores diarios literarios de Euro$p a$, publicó una "Disertación sobre la libertad de escribir" que es probablemente el primero de los textos dedicados entre nosotros a desenvolver y defender el tema. Foronda comenta que "si no hay libertad de escribir y decir cada uno su parecer en todos los asuntos, a reserva de los dogmas de la religión católica y determinaciones del Gobierno, todos nuestos conocimientos yacerán en un eterno olvido"'; no cabe ocultar que sin ella, "las leyes vulnerarán los derechos de propiedad, liber" tad y seguridad; estos tres sublimes principios que son la base del edificio de las leyes, estarán atestados de monstruosidades" 64.

También aquí se encuentra un máximo fervor en la defensa de la libertad de pensamiento, junto a la prudente exclusión de las dos esferas, sin osar participar en abatir el poder irresponsable y opresor. $\mathrm{Ni}$ la libertad, ni por tanto sus frutos en el terreno de la economía y de la ciencia, eran en modo alguno posibles. Claro que esto no quiere decir que la libertad de pensamiento y la libertad de prensa - y conviene recordarlo hoy entre nosotros, cuando algunos se muestran a diario ignorantes de algo que pertenece a la naturaleza misma de los derechos individuales - no tengan, en efecto, sus constitutivas limitaciones. Re-

61 Loc. cit.

62 Obras de Jovellanos, t. 1, BAE, 46, p. 275.

63 G.M. DE Jovellanos, Diarios, t. 3, BAE, 87; p. 364.

64 Valentín DE Foronda, Espiritu de los mejores Diarios, 1789, t. 6, pp. 1 y 12. 
cuérdese el artículo 11 de la Declaración francesa de 1789, probablemente el mejor texto que aún existe en la materia: "La libre comunicación de pensamiento y de opiniones es uno de los derechos más preciados del hombre; en consecuencia, todo ciudadano puede hablar, escribir, imprimir libremente, siendo responsable del abuso de esta libertad en los casos determinados por la ley".

Sin embargo, antes de que termine el siglo de la Ilustración nos será posible hallar algunas manifestaciones más decididas, que llegan a eliminar - por lo menos, no mencionándolos- esos reductos que parecían impenetrables a la libertad de discusión, de opinión, de pensamiento, de conciencia, fórmulas todas éstas entre las que cabe señalar algunas diferencias de matiz, aunque en fin de cuentas todas se comprendan en la libertad de expresar públicamente, por vía oral o por impresos, el pensamiento del individuo.

La situación en España era poco propicia, pero, de todos modos, se llegó por lo menos a hacer pública la defensa de esa libertad, más que a aplicarla, en algunos puntos graves: se alcanza a extenderla incluso a los derechos de la soberanía y la autoridad en lo espiritual de la Iglesia. León de Arroyal - a quien considero uno de los más radicales escritores españoles hacia el final de la centuria- expone con acritud y energía, en su análisis, la situación: "La ciudad metrópoli tiene más templos que casas, más sacerdotes que seglares, y más aras que cocinas"; por todas partes, hasta en infames tabernas y sucios portales, se ven retablitos, pilas de agua bendita; pululan cofradías, procesiones, rosarios cantados, carteles de novenarios y relaciones de milagros, frailezuelos predicadores sin más bagaje que su ignorancia; por el contrario, mientras, permanecen en estado de barbarie o de abandono los estudios de ciencias sagradas, y lo que es más triste y gravemente pernicioso para la sociedad, la filosofía permanece ajena a la observación de la naturaleza, entregada a la más torpe discusión escolástica (lo que nos hace sospechar en el autor una línea buffoniana, posible ya en sus fechas). Y añade el autor: "la Iglesia, en España, siempre contra la razón, contra la libertad de conciencia, negando al pueblo incluso las Santas Escrituras: por todas partes, delirios, sueños, mentecateces, en fin, "influjo frailesco" "65. Frente a esto, observa Arroyal, tan sólo "la controversia es el crisol de las verdades" 66 . Arroyal coloca en un plano político, plenamente tal, esta capacidad de discutir, legalmente reconocida, que es la verdadera naturaleza de la libertad de pensamiento como libertad política. Y para aclarar la cuestión lleva a cabo la penosa com-

65 Pan y toros, folleto del que Arroyal es autor, según puso en claro François Lopez, y del cual ha hecho una edición, junto con otros "papeles" revolucionarios, A. Elorza, Madrid, 1971, pp. 19 y 24-25.

66 León de Arroyal, Cartas económico-políticas. El pasaje citado pertenece a la Carta $\checkmark$ de la segunda serie, descubierta y publicada por Caso González, Oviedo, 1971, p. 248 (la fecha de la carta es 1794). 
paración que a fines del XVIII pasa como ejemplo en el régimen de esta fundamental libertad del ciudadano: Inglaterra. Allí,

la libertad de pensar, la libertad de escribir, la libertad de hablar, crean hasta en el bajo pueblo un espíritu de confianza e interés mutuo que nosotros apenas podemos comprender. Los partidos de oposición, principal fuente de la felicidad inglesa, no dejan pasar cosa sin controvertirla ni permiten providencia que antes no se haya examinado y desmenuzado por todas partes; y como el público es testigo de las grandes deliberaciones del Parlamento y sólo por un acaso se oculta a su vista algún pequeño manejo del Gabinete, jamás desconfía ni le queda ocasión de cavilar sobre ellas... Pero un español, al contrario: toda su vida la pasa entre la desconfianza y el temor, sospechando cada instante una tormenta ${ }^{67}$.

Esto lleva a Arroyal a condenar "la impenetrabilidad del Ministerio", a causa de la cual es imposible que se desarrolle en libertad una opinión cultivada e interesada en el bien de la patria.

Un planteamiento similar a este último se encuentra on un pasaje del prólogo que el traductor anónimo de la Aritmética política de Davenant insertó en cabeza del volumen de Arriquibar en que ésta se publica: la libertad de pensamiento y discusión en Inglaterra permite que allî " uno discurre sobre un asunto; otro sobre otro; lo que aquél yerra, lo impugna y reforma éste; la misma variedad de opiniones contribuye eficazmente a que renazca la verdad, acrisolada en la controversia de cualquier punto" 68 .

Y entre otros juicios semejantes, que coinciden, además, en el punto de que hay que fijarse en la nación que se juzga como ejemplar en el último cuarto del siglo xviII, volviendo atrás nos reduciremos al testimonio de los elogios, superiores a cualesquiera otros, que dedica a Inglaterra, en la materia que hemos tomado en estas páginas como tema, Tomás de Iriarte, en la epístola VIa ${ }^{a}$, dirigida en 1777 a su hermano Domingo:

Allí será preciso que te asombres

De ver, cual no habías visto en parte alguna,

Obrar y hablar con libertad los hombres ${ }^{69}$.

Quiero dedicar los últimos párrafos a rectificar un juicio que fácilmente se hace sobre el fracaso de las Sociedades económicas de Amigos del País y su inutilidad en todos los casos. No es ello cierto, ya que muchas de ellas, entre otras obras que realizaron o gérmenes que dejaron en vía de crecimiento, llevaron a cabo una fecunda siembra ideológica,

67 Ibid., Carta IV de la primera serie, pp. 156-157.

68 N. DE ARRIQUibar, Recreación política. Reflexiones sobre el amigo de los hombres en su tratado de población, Vitoria, 1779.

69 Tomás de Iriarte, $B A E, 63$, p. 32. 
lo cual provocó el ataque gubernamental para su desprestigio. Un caso así se da en lo referente a la proclamación del derecho a la expresión libre del pensamiento. La Sociedad Matritense, cuando recibe la comunicación oficial para que informe sobre el proceso de su decadencia, que el Consejo Real da por supuesto, rechaza que esa imputación sea justa y que se deba a parcialidades surgidas en su seno, ya que en ella "la única división es división o diversidad de opiniones, muy útil en materias dudosas para una investigación de la verdad'. La Sociedad Matritense se muestra tan celosa de la libertad que al presentarse en ella un escrito para que se haga saber a nuevos socios que a nadie se fuerza a entrar en ella, pero si se entra hay que cumplir con las obligaciones del puesto, la sociedad hace añadir: "no es esto coartar la libertad del individuo"; y en su seno, la Clase de Agricultura, al redactar la parte que le corresponde sobre su estado, pide que los socios hablen "con aquella libertad que debe reinar en todo país donde ha establecido su imperio la filosofía"70. La Sociedad Bascongada en Vergara recuerda que "las controversias animan el celo de los socios"71. La Sociedad de Cuenca proclama que "la interna libertad de pensar no reconoce humano señorio" 72 - donde "interna" no quiere decir callada o que no se hace escuchar, sino que no admite más apelación que la propia conciencia. En la Sociedad de Segovia, el activo e inteligente Vicente Alcalá Galiano, en una "Memoria" escrita en colaboración con Matecón, introduce este principio: "sin ella lla libertad], los hombres no niensan, discurren ni adelantan en ningún ramo" "73. Y Manuel de Aguirre, representante del Amigo del País por excelencia, individuo de la Sociedad Matritense, la Aragonesa y la Bascongada, reclamará "libertad de pensar por sí" 74 , frase que recuerda sendas exhortaciones de Voltaire y de Kant que antes reproduje $\mathrm{e}^{75}$. Todavía dentro del ámbito societario, Cabarrús, en su 'Elogio del conde de Gausa', exigirá que, en relación con las operaciones del gobierno, "se debe conceder la mayor libertad en la discusión" 76 .

70 Jorge y Paula Demerson, La decadencia de las Reales Sociedades Económicas de Amigos del País, Oviedo, 1978, pp. 41 y 77.

71 Ibid., p. 42.

72 Ibid., p. 43.

73 Actas de la Sociedad Económica de Segovia, 1787, t. 3, p. 33, nota al pie de la segunda "Memoria" que dicho volumen contiene (las dos "Memorias" que lo integran llevan numeración separada). El título de este escrito es Perjuicios del antiguo sistema de rentas provinciales y utilidades y ventajas del que se establece por los nuevos reglamentos.

74 Cartas y discursos del militar ingenuo al Correo de los ciegos en Madrid, ed. A. Elorza, San Sebastián, 1974; véase también A. ElorzA, La ideología liberal..., ed. cit.

75 Sobre este tópico - porque así puede llamarse por su antiguo origen y larga subsistencia- véase el estudio de Franco Venturi, incluido en su obra Europe des Lumières, 1971, pp. 35 ss.

76 "Elogio del conde de Gausa", pronunciado ante la Real Sociedad Económica Matritense, Madrid, 1786. Véase mi estudio "Cabarrús y las ideas de reforma política y social en el siglo XVII', ROcc, 23 (1968), 290-291. 
En su valiosa obra doctrinal, Cartas sobre los obstáculos que la naturaleza, la opinión y las leyes oponen a la felicidad pública, el conde de Cabarrús combate una vez más la tradición y la autoridad, cuando aparecen imponiéndose contra el discurso racional, y advierte que atenerse a éste les valió el éxito en sus empresas a aventajados precursores: "la meditación les hizo descubrir aquellas verdades elementales, casi totalmente oscurecidas, y la verdadera ciencia, apoyada en la duda y el análisis, restituyó a la naturaleza sus luces primitivas". Hay que garantizar al ciudadano "la más libre comunicación de sus luces" 77 .

$\mathrm{Y}$ para terminar quiero hacer observar que si en determinados aspectos, en lo moral, político y económico, quedan amargos juicios sobre el estado que se contempla - ahí está como ejemplo la exacerbación crítica de Goya por la ignorancia y las viciosas costumbres que los que mandan no están dispuestos a combatir, por la opresión frailuna o inquisitorial, por la depravación de parte de la nobleza, por la miseria degradante de tantos pobres y la estúpida vanidad del privilegiado-; sin embargo, aparecen opiniones positivas sobre lo que en conjunto han adelantado las ciencias y la más libre posibilidad de difundirlas. Sempere y Guarinos celebra que desaparezca el dogmatismo y ceda el espíritu de partido guardado en las viejas instituciones; sólo así puede alcanzar "el entendimiento bastante libertad y desembarazo para pensar y para explicarse" ${ }^{78}$. En su famoso repertorio bibliográfico de contemporáneos incluye un pasaje del ilustre "patriota" Antonio de Capmany - redactor más tarde del resumen de los informes sobre la celebración de Cortes que la Junta Suprema ordenara-, un pasaje que constituye en el campo que examino aquí el juicio tal vez más favorable que se escucha en medio del estrepitoso cambio de épocas. Capmany afirma, y en algún momento debió creerlo sinceramente: "brillan las ciencias exactas, reina la filosofía, se restablecen los derechos respectivos a la humanidad, hasta aquí poco atendida, se descubre la libertad de decirla"79.

Capmany, en cierto modo, tenía razón. Hay en sus palabras, ciertamente, un exceso difícilmente explicable de optimismo. Pienso que en parte procedía de un lejano eco de los Éléments de philosophie de d'Alembert. Hacia ese optimismo era arrastrado el autor por el lenguaje ilustrado y dieciochesco que empleaba. Pero una cosa es innegable, desde entonces no desaparecería ya del campo de batalla político la libertad de expresar el propio pensamiento, y aunque tantas veces en nuestra

77 Véanse la segunda de las Cartas mencionadas y mi artículo citado en la nota precedente, p. 291.

78 Juan Sempere y Guarinos, Ensayo de una biblioteca española de los mejores escritores del reinado de Carlos III, 1785. Ed. facs. Madrid, 1969, t. 1, "Discurso preliminar', p. 32. Sempere considera que Carlos III ha restituido "a los grandes talentos la justa y prudente libertad", p. 33.

79 Antonio de CAPMANY, Discursos analíticos sobre la formación y perfección de las lenguas y sobre la castellana en particular, resumido por Sempere en su mencionada Biblioteca, t. 2, p. 143, donde reproduce un extenso párrafo del "Discurso" de Capmany; en él 
historia perdiera el combate esa libertad, nunca dejaríamos de verla reaparecer, algo más tarde, habiendo ganado un poco más de terreno.

José A. Maravall

dice este autor que ello se debe a que "el siglo pasado era la edad de la imaginación [...]. Éste es el de la razón". 